\title{
Cohesion and performance in soccer: A causal model
}

\author{
Aristotelis GIOLDASIS • Nektarios STAVROU・ \\ Michael MITROTASIOS • Maria PSYCHOUNTAKI
}

\begin{abstract}
The conceptual model of sport cohesion that Carron developed describes the relationships between cohesion and performance including the antecedents and consequences of the variables. Although researchers have conducted a plethora of studies around the relationship between cohesion and performance, there is a gap in literature regarding longitudinal changes of this relationship as well as its direction. Therefore, the aim of the current study is to examine the relationship between cohesion and performance for soccer teams during a full competitive season as well as the direction of the relationship. The study suggests a new model for the relationship between cohesion and performance. In total, 173 Greek soccer players $(\mathrm{M}=21.91)$ completed the Group Environment Questionnaire (Carron et al., 1985) in all the measurements from the beginning of the preparation to the end of the competitive season. The results showed that cohesion and performance are two variables that affect each other in soccer, with a stronger direction from cohesion to performance. However, cohesion affects performance either positively or negatively throughout the season.
\end{abstract}

Keywords: soccer, football, cohesion, performance, longitudinal, GEQ 


\section{Introduction}

In soccer it is hard to explain why teams with a significant number of talented and skillful players are unable to demonstrate elite performance. A simple but essential approach has been suggested by the Swedish coach SvenGöran Eriksson who stated that team mentality benefit both individual and team performance (Eriksson, 2003). In sport psychology, the mentality that coach Eriksson describes is called cohesion. Cohesion is defined as the dynamic process that is reflected in the tendency of a group to stick together and remain united in its pursuit of instrumental objectives and/or for the satisfaction of members' affective needs (Carron, Brawley, \& Widmeyer, 1998, pp. 213). The nature of cohesion is considered to be dynamic throughout the team building stages (Carron \& Brawley, 2000). The demands, the responsibilities and the needs of the team members change throughout a season. Therefore, Tuckman first described the stages of forming, storming, norming and performing that teams pass (Tuckman, 1965; Tuckman \& Jensen, 1977). Although many findings support the dynamic role of cohesion (Grieve, Whelan, \& Meyers, 2000; Kozub \& Button, 2000), others affirm a constant role (Chang \& Bordia, 2001; Dunlop, Falk, \& Beauchamp, 2013). Sport psychology researchers have indicated a high number of studies concerning cohesion related factors. Thus, a plethora of studies around the relationship between cohesion and performance have been conducted. Although most of them conclude a positive relationship between the variables (Carron, Bray, \& Eys, 2002a; Carron, Colman, Wheeler, \& Stevens, 2002b; Evans \& Dion, 2012; Kozub \& Button, 2000; Narimani \& Ahari, 2008; Pain \& Harwood, 2008), others suggest a non-significant one (Maynard \& Watson, 1995; Tziner, Nicola, \& Rizac, 2003), a negative (Hardy, Eys, \& Carron, 2005), and even an inverse 'U' relationship (Wise, 2014). Carron developed the conceptual model of sport cohesion, which combined cohesion and performance including the antecedents and consequences (Carron, 1982; Carron et al., 1998). Sport cohesion is a multidimensional construct that can be divided into two different dimensions: the social and the task cohesion. The task cohesion corresponds to the desire of group members to work towards the achievement of the team goals, while social cohesion corresponds to the need of group members to form and maintain interpersonal bonds. The conceptual model consists of the following dimensions of task and social cohesion: individual attraction to the group-task (ATG-T), individual attraction to the group-social (ATG-S), group integration-task (GI-T), and group integrationsocial (GI-S). However, the meta-analysis of Carron and colleagues (2002b) revealed that many studies which used the two main dimensions of cohesion, task and social, as well as the four dimensions demonstrate reliability problems (Carron, et al., 2002b; Heuzé, Raimbault, \& Fontayne, 2006; Leo, GonzálezPonce, Amado, Pulido, \& García-Calvo, 2013; Leo, Sánchez-Miguel, Sáchez- 
Oliva, Amado, \& García-Calvo, 2012). Concerning the relationship between cohesion dimensions and performance, it was found that although findings suggest that the relationship between task cohesion and performance is similar to the relationship between social cohesion and performance (Carron et al., 2002b), others suggest that task cohesion is related closer to performance than social cohesion does (Kozub \& Button, 2000; Salminen \& Luhtanen, 1998; Williams \& Widmeyer, 1991). However, other findings suggest that social cohesion is related more to performance than task cohesion does (Bray \& Whaley, 2001; Slater \& Sewell, 1994), or that social cohesion is perceived as a negative factor of performance more frequently than task cohesion (Hardy et al., 2005).

Another point that is increasingly interesting is the direction of the relationship between cohesion and performance. Although the conceptual model of group cohesion indicates a direction from cohesion to performance, many findings reveal an opposite direction or a cyclic relationship between the variables (Grieve et al., 2000; Leo et al., 2013; Narimani \& Ahari, 2008). An explanation about this conflict of findings was probably added by a metaanalysis of Carron and colleagues (2002b), who revealed that the relationship between cohesion and performance depends on the sport, the methodological approach and the parameters of variable evaluations (Carron et al., 2002b; Mullen \& Copper, 1994). For example, performance was evaluated according to the result (Grieve et al., 2000; Kozub \& Button, 2000; Tziner et al., 2003), the league points (Carron et al., 2002a; Salminen, \& Luhtanen, 1998), or the ranking (Leo et al., 2013; Leo, García-Calvo, Parejo, Sánchez-Miguel, \& Sánchez-Oliva, 2010; Ramzaninezhad, Keshtan, Shahamat, \& Kordshooli, 2009).

Thus, a design that would compare changes of cohesion and performance longitudinally is needed. The aim of the current study has been to examine the relationship between cohesion and performance for soccer teams during a full competitive season. The study examines the following causal model (Figure 1):

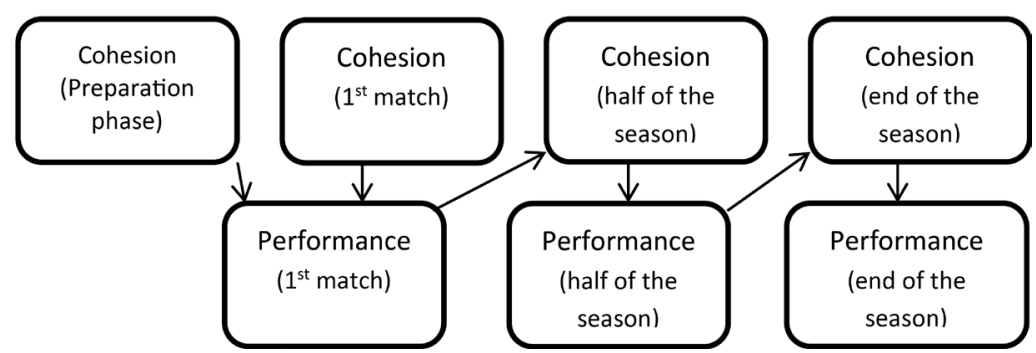

Figure 1. Causal relationships between cohesion and performance. 


\section{Methods}

\section{Participants}

In this study, 173 male players of Greek amateur leagues in Athens and Arcadia (Greek region) for the season 2009-2010 participated. The participants' age ranged from 13 to $38(\mathrm{M}=21.91, \mathrm{SD}=5.49)$. Sixteen teams, consisting of around 20 members each, took part in the study. All the players were practicing at least 4 times per week, playing 1 game each weekend. The researchers informed both the players and the coaches about the aims, the procedure, the requirements, the benefits and the ethics of the study before completing an informed consent form. The University Research Ethics Committee granted approval for the current study.

\section{Design}

The selection of the teams that would participate in the study performed before the beginning of preparation during summer. The methodology was based on the stages of team building that Tuckman described (Tuckman, 1965; Tuckman \& Jensen 1977). The measurements of cohesion was performed (a) at the beginning of the preparation, (b) at the beginning of the season, (c) at the middle and (d) at the end of the season while performance was measured (a) at the beginning of the season, (b) at the middle and (c) at the end of the season.

\section{Measurements / Questionnaires}

The perceptions of team cohesion were assessed with the Greek version of the 18-item Group Environment Questionnaire (GEQ: Carron et al., 1985; Angelonidis, 1995). The Group Environment Questionnaire assesses the four dimensions of cohesion. Individual Attractions to the Group-Task (ATG-T) is the factor, which identifies team-members individual perceptions with regard to their personal involvement to the task. Individual Attractions to the Group-Social (ATG-S) is the factor, which identifies team-members individual perceptions in relation to their personal involvement, acceptance and social interaction to the team as a whole. Group Integration-Task (GI-T) is the factor, which identifies the team-members individual perceptions on identity, closeness and bonding within the whole group. Group Integration-Social (GI-S) is the factor, which identifies the individual perceptions of the team members on identity, closeness and bonding within the whole group but with regards to its social aspects. Participants rate their consent to items on a 9-point scale anchored by 1 ('strongly disagree') to 9 ('strongly agree'). The reliability coefficients of the Greek version of the questionnaire with sample of team sports 
were .72 (ATG-T), .75 (ATG-S), .75 (GI-T) and .79 (GI-S). In the current study the researchers were only interested in two dimensions of cohesion, task and social, which associated better with performance. Team performance was assessed by game result, league ranking and league points in the weekend following the evaluation of cohesion.

\section{Procedures}

The researchers contacted soccer coaches before the preparation period so as to inform them about ethics, risks and benefits of the study and obtain permission to meet the players. Then they discussed all the questions with the players on predefined days. Before giving the questionnaires, written informed consents were taken from all the players that agreed to participate. The researchers instructed them on how to fill in the questionnaires and assured them of the confidentiality of the survey. After the end of the study, they presented their conclusions about each team's cohesion to the training staff.

\section{Statistics}

All statistical analyses were performed using the SPSS package (v. 17). The techniques employed were (a) descriptive statistics for all measurements of cohesion, (b) correlations between the variables and (c) hierarchical multiple regression analyses to identify the relationship between cohesion and performance.

\section{Results}

The Cronbach alpha of the Group Environment Questionnaire was satisfied for all the measurements of the factors. Table 1 summarizes the descriptive statistics of task and social cohesion for all the measurements. 
Cohesion and performance in soccer: A causal model

\begin{tabular}{crrrrrrr}
\hline Cohesion & $\mathbf{M}$ & $\mathbf{S D}$ & $\mathbf{S k}$ & $\mathbf{K u}$ & $\mathbf{M i n}$ & $\mathbf{M a x}$ & Cronbach $\alpha$ \\
\hline Preparation & & & & & & & \\
T-Cohesion & 60.40 & 10.87 & -.45 & .03 & 21 & 81 & 71 \\
S- Cohesion & 55.21 & 10.73 & -.144 & -.01 & 19 & 81 & 67 \\
$1^{\text {st }}$ game & & & & & & & \\
T- Cohesion & 58.93 & 11.06 & -.30 & -.48 & 23 & 81 & 72 \\
S- Cohesion & 55.16 & 10.12 & .18 & -.22 & 26 & 81 & 69 \\
$15^{\text {th }}$ game & & & & & & & 83 \\
T- Cohesion & 54.65 & 13.70 & -.38 & -.33 & 16 & 79 & 81 \\
S- Cohesion & 55.12 & 11.94 & -.18 & -.01 & 20 & 81 & 83 \\
$30^{\text {th }}$ game & & & & & & & 81 \\
T- Cohesion & 52.76 & 12.96 & -.09 & -.35 & 17 & 81 & 81 \\
S- Cohesion & 54.87 & 11.94 & -.10 & .13 & 19 & 81 & 82 \\
\hline
\end{tabular}

Table 1 - Cronbach alpha and descriptive statistics of task cohesion (T-Cohesion) and social cohesion (S-Cohesion) for all the measurements.

The following table shows the correlations between performance measurements and cohesion factors. It is obvious that performance and cohesion are at their highest point in the middle of the season. The minus signs of result and ranking columns represent a positive relationship between performance and cohesion while the plus represent a negative relationship (Table 2). 
Sport Science Review, vol. XXV, No. 1-2, May 2016

Performance

\begin{tabular}{|c|c|c|c|c|c|c|}
\hline \multirow[b]{2}{*}{ Cohesion } & \multicolumn{2}{|c|}{ 1st game } & \multicolumn{2}{|c|}{ 15th game } & \multicolumn{2}{|c|}{ 30th game } \\
\hline & Ranking & Points & Ranking & Points & Ranking & Points \\
\hline \multicolumn{7}{|l|}{ Preparation } \\
\hline T-Cohesion & -.12 & -.02 & $.16^{*}$ & $-.20 * *$ & $.15^{*}$ & $-.18^{*}$ \\
\hline S-Cohesion & .07 & $-.22^{* *}$ & .13 & -.06 & .10 & -.07 \\
\hline \multicolumn{7}{|l|}{ 1st game } \\
\hline T-Cohesion & $-.19 * * *$ & $.14^{*}$ & -.10 & .03 & -.09 & .04 \\
\hline S-Cohesion & -.04 & -.05 & -.03 & .01 & .02 & -.04 \\
\hline \multicolumn{7}{|l|}{ 15th game } \\
\hline T-Cohesion & $-.48^{* * *}$ & $.36^{* * *}$ & $-.43^{* * *}$ & $.34^{* * *}$ & $-.29 * * *$ & $.29 * * *$ \\
\hline S-Cohesion & $-.28 * * *$ & $.20^{*}$ & $-.39 * * *$ & $.32^{* * *}$ & $-.31 * * *$ & $.27 * * *$ \\
\hline \multicolumn{7}{|l|}{ 30th game } \\
\hline T-Cohesion & -.14 & $.18^{*}$ & $-.19 * *$ & .14 & $-.21 * *$ & $.19^{* *}$ \\
\hline S-Cohesion & -.04 & .06 & -.18 & .14 & $-.17 *$ & .13 \\
\hline$* \mathrm{p}<.05$ & $* * \mathrm{p}<.01$ & $* * * \mathrm{p}<.001$ & & & & \\
\hline
\end{tabular}

Table 2 - Correlations between cohesion and performance.

The Table 3 shows the hierarchical multiple regression analysis that was used to examine the prediction of performance by cohesion. The results of the regression indicated that cohesion explained $22 \%$ of final league points variance $(\mathrm{R} 2=.22, \mathrm{~F}=5.70, \mathrm{p}<.001)$. It was found that task cohesion of preparation significantly predicted the final league points $(\beta=-.35, \mathrm{p}<.01)$, as did social cohesion at the beginning of the season $(\beta=-.29, \mathrm{p}<.05)$, and social cohesion in the middle of the season $(\beta=.48, \mathrm{p}<.01)$. The cohesion also explained $23 \%$ of middle season league points variance $(\mathrm{R} 2=.23, \mathrm{~F}=8.43, \mathrm{p}<.001)$. The middle season league points were affected by task cohesion of preparation $(\beta=$ $.38, \mathrm{p}<.001)$, task cohesion and social cohesion in the middle of the season $(\beta=.27, \mathrm{p}<.05 ; \beta=.26, \mathrm{p}<.05)$ respectively. The cohesion also explained $24 \%$ of final ranking variance $(\mathrm{R} 2=.24, \mathrm{~F}=6.38, \mathrm{p}<.001)$. It was found that task 
cohesion of preparation $(\beta=.30, \mathrm{p}<.01)$, task cohesion at the beginning of the season $(\beta=-.28, p<.05)$, social cohesion at the beginning of the season $(\beta=$ $.30, \mathrm{p}<.05)$ and social cohesion in the middle of the season $(\beta=-.59, \mathrm{p}<.001)$ significantly predicted the final ranking. Finally, cohesion explained the $32 \%$ of middle season ranking variance $(\mathrm{R} 2=.32, \mathrm{~F}=12.88, \mathrm{p}<.001)$. The middle season ranking was predicted by task cohesion of preparation $(\beta=.27, \mathrm{p}<.05)$, task cohesion and social cohesion in the middle of the season $(\beta=-.25, \mathrm{p}<.05$; $\beta=-.37, \mathrm{p}<.01)$ respectively.

\begin{tabular}{|c|c|c|c|c|c|c|c|c|}
\hline \multirow{3}{*}{ Cohesion } & \multicolumn{4}{|c|}{ 30th game } & \multicolumn{4}{|c|}{ 15th game } \\
\hline & \multicolumn{2}{|c|}{ Points } & \multicolumn{2}{|c|}{ Ranking } & \multicolumn{2}{|l|}{ Points } & \multicolumn{2}{|c|}{ Ranking } \\
\hline & Beta & $\beta$ & Beta & $\beta$ & Beta & $\beta$ & Beta & $\beta$ \\
\hline $\begin{array}{l}\text { Preparation } \\
\text { T-Cohesion }\end{array}$ & -.38 & $-.35^{* *}$ & .09 & $.30 * *$ & -.23 & $-.38 * * *$ & .09 & $.27 *$ \\
\hline S-Cohesion & .10 & .09 & .01 & .02 & .03 & .05 & .05 & .16 \\
\hline \multicolumn{9}{|l|}{ 1st game } \\
\hline T-Cohesion & .22 & .20 & -.08 & $-.28 *$ & .08 & .14 & -.05 & -.16 \\
\hline S-Cohesion & -.35 & $-.29 *$ & .10 & $.30^{*}$ & -.11 & -.17 & .05 & .13 \\
\hline \multicolumn{9}{|l|}{$15^{\text {th }}$ game } \\
\hline T-Cohesion & .09 & .11 & .00 & .00 & .13 & $.27 *$ & -.06 & $-.25^{*}$ \\
\hline S-Cohesion & .47 & $.48^{* *}$ & -.16 & $-.59 * * *$ & .14 & $.26^{*}$ & -.11 & $-.37 * *$ \\
\hline \multicolumn{9}{|l|}{$30^{\text {th }}$ game } \\
\hline T-Cohesion & .08 & .09 & -.02 & -.08 & - & - & - & - \\
\hline S-Cohesion & -.21 & -.21 & .05 & .19 & - & - & - & - \\
\hline $\mathrm{F}$ & \multicolumn{2}{|c|}{$5.70 * * *$} & \multicolumn{2}{|c|}{$6.38 * * *$} & \multicolumn{2}{|l|}{$8.432^{* * *}$} & \multicolumn{2}{|c|}{$12.877 * * *$} \\
\hline $\mathrm{R}^{2}$ & \multicolumn{2}{|l|}{.22} & \multicolumn{2}{|l|}{.24} & \multicolumn{2}{|l|}{.23} & \multicolumn{2}{|l|}{.32} \\
\hline$* \mathrm{p}<.05^{* *}$ & \multicolumn{2}{|c|}{$\mathrm{p}<.01 * * *$} & \multicolumn{2}{|c|}{$\mathrm{p}<.001$} & & & & \\
\hline
\end{tabular}

Table 3 - Performance predictors.

The Table 4 shows the hierarchical multiple regression analysis that was used to examine the prediction of cohesion by performance. The results of the regression indicated that performance explained $8 \%$ and $9 \%$ of task cohesion and social cohesion at the end of the season $(\mathrm{R} 2=.08, \mathrm{~F}=2.25, \mathrm{p}<.01 ; \mathrm{R} 2=$ $.09, \mathrm{~F}=2.46, \mathrm{p}<.01)$ respectively. No performance variable was found affecting cohesion at the end of the season. Performance also explained $18 \%$ and $16 \%$ of task and social cohesion in the middle of the season $(\mathrm{R} 2=.18, \mathrm{~F}=8.10, \mathrm{p}<.001$; $\mathrm{R} 2=.16, \mathrm{~F}=7.10, \mathrm{p}<.001)$ respectively. It was found that ranking in the middle of the season significantly predicted task cohesion in the middle of the season 
$(\beta=-.68, p<.01)$. Finally, both league points and ranking in the middle of the season predicted the social cohesion in the middle of the season $(\beta=-.44, \mathrm{p}<$ $.05 ; \beta=-.95, \mathrm{p}<.001)$.

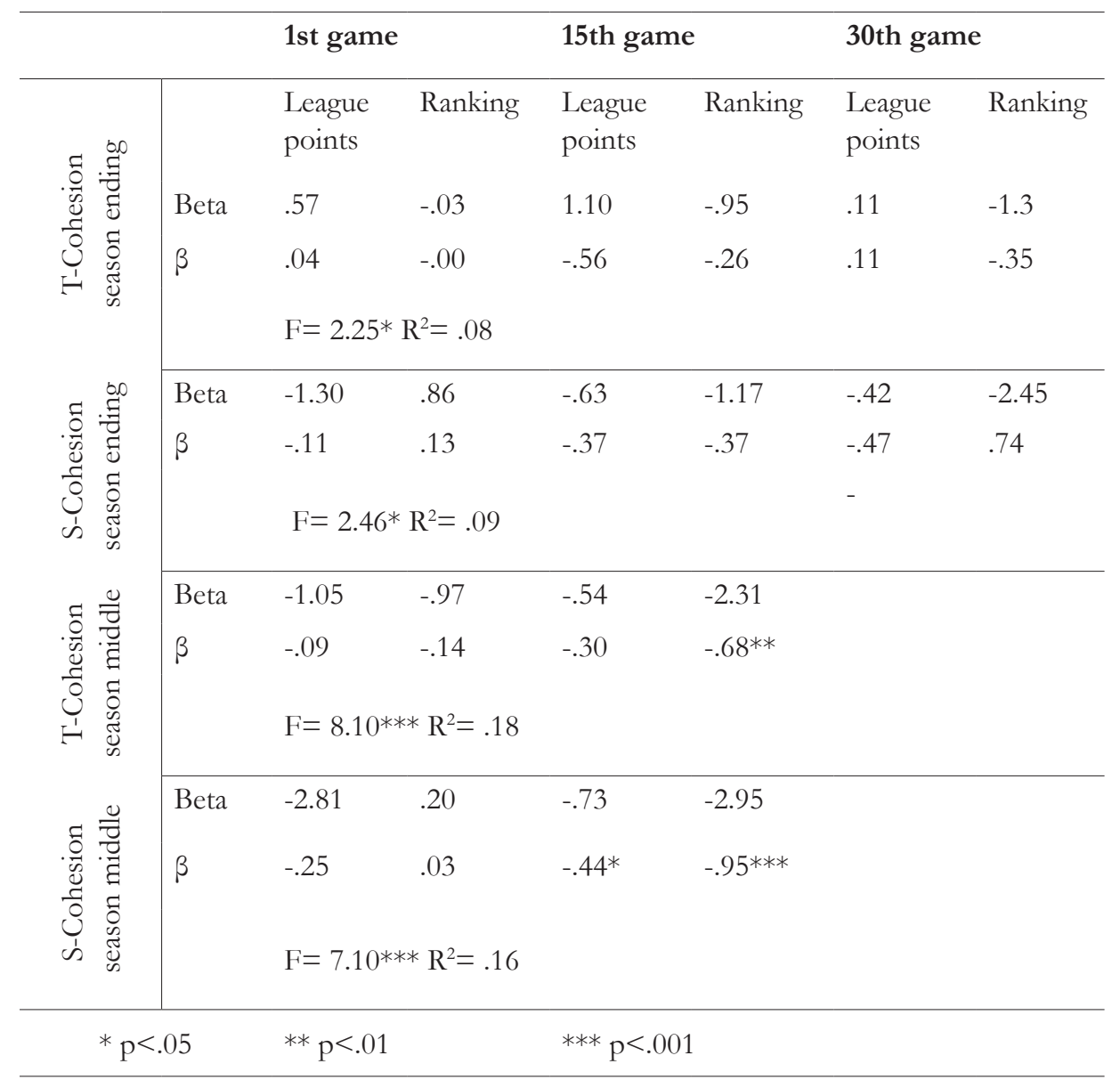

Table 4 - Cohesion predictors.

\section{Discussion}

The main aim of the study has been to identify the relationship between cohesion and performance throughout an entire competitive season. The researchers evaluated cohesion in four different periods of the season so they could also examine the dynamic nature of the variable. Initially, the dynamic role of cohesion was confirmed, but only for task cohesion which was reduced 


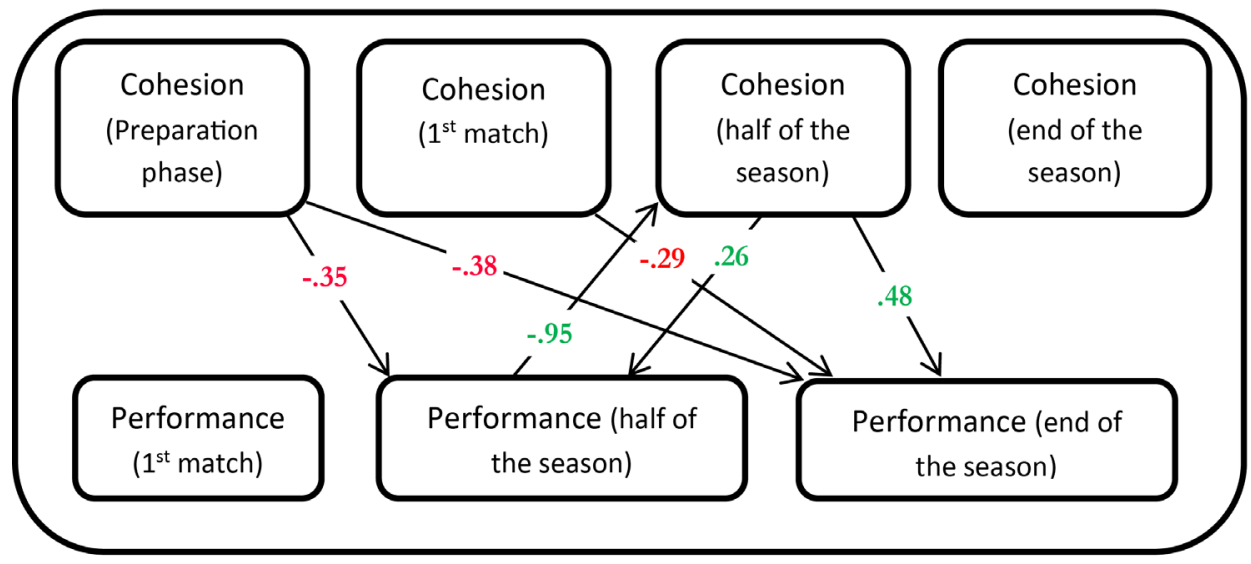

considerably (Kozub \& Button, 2000). Although previous findings support either a stable or a dynamic nature of cohesion the current ones are probably explained by the different antecedents that predict cohesion. For example, it is possible that social cohesion was already at the maximum level either because most of the players had been playing together for many years (Dunlop \& Beauchamp, 2011), or because cohesion is relatively stable once the group is formed (Carron et al., 1998). On the other hand, task cohesion probably reduced throughout the season because of the results and changes of team targets. It was proved that most of the teams that participated in the study targeted higher league positions than the one they achieved, and probably the teams could not reach the principal targets (Johnson et al., 2011). In addition, there is the viewpoint that task cohesion changes while social cohesion is a complex procedure that requires intervention so as to change (Aggelonidis, 1995). According to the correlations between cohesion and performance, it was found that both task and social cohesion in the middle of the season were highly correlated with performance in the middle and at the end of the season. Previous findings also supported this positive relationship between the variables (i.e. Carron et al., 2002a; Carron et al., 2002b; Narimani \& Ahari, 2008). However, in depth analyses revealed a more complicated relationship among the measurements of cohesion and performance (ranking / league points). The regression model showed that, although both variables contribute to the relationship, cohesion predicted performance more than performance did, at all the stages. However, the longitudinal nature of the study revealed that cohesion affected performance negatively or positively depending on the period of measurement and the performance evaluation. Specifically, it was found that task cohesion of the preparation affected team performance in the middle and at the end of the season negatively. This finding is probably explained by the fact that teams set higher targets than they could achieve. Most of the players at the beginning of the preparation targeted the 
top league positions when the researchers examined their season expectations. Moreover, friendlies before the season reveal the realistic targets of the teams, as past outcome creates the expectations of future outcome (Bhattacharya, Devinney, \& Pillutla, 1998). Furthermore, task cohesion at the beginning of the season and in the middle of the season affected positively final and middle season team performance respectively. It is probably explained by the fact that teams changed their targets, a finding that also explains the reduction of task cohesion throughout the season. Concerning the relationship between social cohesion and performance, it was found that social cohesion at the beginning of the season affected performance at the end of the season negatively, while social cohesion in the middle of the season affected team performance in the middle and at the end of the season positively. These findings are probably explained by the fact that teams with high rates of social cohesion at the beginning of the season and probably not enough quality to achieve their goals, their early social cohesion is considered as a leisurely attitude or is related to anxiety (Hardy et al., 2005). It is suggested further research concerning the influence of team cohesion in the beginning of the season and how it affects later cohesion stages. On the other hand, social cohesion in the middle of the season is probably related to performance positively as the targets already satisfied or not and the players perform without any anxiety. As far as prediction of cohesion by performance is concerned, it was found that ranking in the middle of the season affected both task and social cohesion in the middle of the season positively. On the other hand, league points in the middle of the season affected social cohesion negatively in the middle of the season. This conflict among the performance evaluations is probably explained by the fact that league points are not always the best predictor of performance comparing teams of different league level (teams that participated at more or less competitive league levels). The findings concerning the low cohesion prediction by performance are supported by the literature review which argues that performance maintains cohesion and do not affect it significantly (Boone, Beitel, \& Kuhlman; 1997). The findings of the current study suggest that our model describe the relationships between team cohesion and performance throughout a season in soccer. In conclusion, the study showed that cohesion and performance are two variables that affect each other in soccer, with a stronger direction from cohesion to performance. However, cohesion affects performance either positively or negatively throughout the season. Thus, coaches should develop both cohesion and performance, variables that probably related positively when both are at high levels. Future research would be advised to examine the factors that mediate this relationship (i.e. anxiety, collective efficacy). 


\section{References}

Aggelonidis, Y. (1995). Team cohesion and coach leadership style as factors affecting the performance of volleyball teams. Unpublished doctoral dissertation, University of Athens, Greece.

Bhattacharya, R., Devinney, T., \& Pillutla, M. (1998). A formal model of trust based on outcomes. Academy of Management Review, 23, 459-472.

Boone, K. S., Beitel, P., \& Kuhlman, J. S. (1997). The effects of the win/loss record on cohesion. Journal of Sport Behavior, 20, 125-134.

Bray, C. D., \& Whaley, D. E. (2001). Team cohesion, effort, and objective individual performance of high school basketball players. The Sport Psychologist, 15, 260-275.

Carron, A.V. (1982). Cohesiveness in sport groups: Interpretations and considerations. Journal of Sport Psychology, 4, 123-138.

Carron, A. V., \& Brawley, L. R. (2000). Cohesion: Conceptual and measurement issues. Small Group Research, 31, 89-106.

Carron, A. V., Brawley, L. R., \& Widmeyer, W. N. (1998). The measurement of cohesiveness in sport groups. In J. L. Duda (Ed.), Advances in sport and exercise psychology measurement (pp. 213-226). Morgantown, WV: Fitness Information Technology.

Carron, A. V., Bray, S. R., \& Eys, M. A. (2002a). Team cohesion and team success in sport. Journal of Sports Sciences, 20, 119-126.

Carron, A. V., Colman, M. M., Wheeler, J., \& Stevens, D. (2002b). Cohesion and performance in sport: A meta-analysis. Journal of Sport \& Exercise Psychology, 24, 168-188.

Carron, A. V., Widmeyer, W. N., \& Brawley, L. R. (1985). The development of an instrument to assess cohesion in sport teams: The group environment questionnaire. Journal of Sport Psychology, 7, 244-266.

Chang, A., \& Bordia, P. (2001). A multidimensional approach to the group cohesiongroup performance relationship. Small Group Research, 32, 379-405. 
Dunlop, W. L., \& Beauchamp, M. R. (2011). Does similarity make a difference? Predicting cohesion and attendance behaviors within exercise group settings. Group Dynamics: Theory, Research, and Practice, 15, 258-266.

Dunlop, W. L., Falk, C. F., \& Beauchamp, M. R. (2013). How dynamic are exercise group dynamics? Examining changes in cohesion within class-based exercise programs. Health Psychology, 32(12), 1240-1243.

Eriksson, S. G. (2003). Sven Göran Eriksson on Football, Carlton Books.

Evans, C. R., \& Dion, K. L. (2012). Group cohesion and performance: A meta-analysis. Small Group Research, 43(6), 690-701.

Grieve, F. G., Whelan, J. P., \& Meyers, A. W. (2000). An experimental examination of the cohesion-performance relationship in an interactive team sport. Journal of Applied Sport Psychology, 12, 219-235.

Hardy, J., Eys, M. A., \& Carron, A. V. (2005). Exploring the potential disadvantages of high cohesion in sport teams. Small Group Research, 36, 166-187.

Heuzé, J. P., Raimbault, N., \& Fontayne, P. (2006). Relationships between cohesion, collective efficacy, and performance in professional basketball teams: An examination of mediating effects. Journal of Sports Sciences, 24, 59-68.

Johnson, S. R., Wojnar, P. J., Price, W. J., Foley, T. J., Moon, J. R., Esposito, E. N., \& Cromartie, F. J. (2011). A coach's responsibility: Learning how to prepare athletes for peak performance. Sport Journal, 14 (1), 1-3.

Kozub, S. A., \& Button, C. J. (2000). The influence of a competitive outcome on perceptions of cohesion in rugby and swimming teams. International Journal of Sport Psychology, 31, 82-95.

Leo, F. M., García-Calvo, T., Parejo, I., Sánchez-Miguel, P. A., Sánchez-Oliva, D. (2010). Interaction of cohesion and perceived efficacy, success expectations and performance in basketball teams. Revista de investigación en Psicología del Deporte, 19, 89-102.

Leo, F. M., González-Ponce, I., Amado, D., Pulido, J. J., \& García-Calvo, T. (2013). Multilevel analysis of evolution of group process and their relation to setting goals and performance in semiprofessional soccer. Journal of Human Kinetics, 39, 221-229. 
Leo, F. M., Sánchez-Miguel, P. A., Sáchez-Oliva, D., Amado, D., \& GarcíaCalvo, T. (2012). Evolution of perceived cohesion and efficacy over the season and their relation to success expectations in soccer teams. Journal of Human Kinetics, 34, 129-138.

Maynard, I. W., \& Watson, J. C. (1995). Cohesion and performance in elite male basketball players. Journal of Sport Sciences, 13, 66-67.

Mullen, B., \& Copper, C. (1994). The relation between group cohesiveness and performance: An integration. Psychological Bulletin, 115, 210-227.

Narimari, M., \& Ahari, S. S. (2008). A study of the relationship between team cohesion, role ambiguity and athletic performance in football team players. Research Journal of Biological Sciences, 3, 47-51.

Pain, M. A., \& Harwood, C. G. (2008). The performance environment of the England youth soccer teams: A quantitative investigation. Journal of Sports Sciences, 26, 1157-1169.

Ramzaninezhad, R., Keshtan, M. H., Shahamat, M. D., Kordshooli, S. S. (2009). The relationship between collective efficacy, group cohesion and team performance in professional. Brazilian Journal of Biomotricity, 3, 31-39.

Salminen, S., \& Luhtanen, P. (1998). Cohesion predicts success in junior ice hockey. Perceptual \& Motor Skills, 87, 649-650.

Slater, M. R., \& Sewell, D. F. (1994). An examination of the cohesion-performance relationship in university hockey teams. Journal of Sports Sciences, 12, 423431.

Tziner, A., Nicola, N., \& Rizac, A. (2003). Relation between social cohesion and team performance in soccer teams. Perceptual \& Motor Skills, 96, 145-148.

Tuckman, B. W. (1965). Developmental sequence in small groups. Psychological Bulletin, 63, 384-399.

Tuckman, B. W., \& Jensen, M. A. (1977). Stages of small group development revisited. Group \& Organizational Studies, 2, 419-427.

Williams, J. M., \& Widmeyer, W. N. (1991). The cohesion-performance outcome relationship in a coacting sport. Journal of Sport \& Exercise Psychology, 13, 364371.

Wise, S. (2014). Can a team have too much cohesion? The dark side to network density. European Management Journal. 


\section{Gioldasis ARISTOTELIS}

Undergraduate degree in Physical Education and Sport Science from Kapodistrian University of Athens. Specialty in Soccer Coaching. Specialty in Sports Management. Master (2 year full-time MSc) in Sport Psychology, "Physical Education and Sport" with major in Social and Behavioural Studies, from Kapodistrian University of Athens PhD student in University of Peloponnese "School of Human Movement and Quality of Life Sciences"

\section{Correspondence address:}

Aristotelis Gioldasis; Lachana 14-16, 11362

Athens; Greece

E-mail: giold_telis@yahoo.gr

Tel: +306906511661

\section{Stavrou NEKTARIOS}

1st undergraduate degree in Physical Education and Sport Science from Kapodistrian University of Athens. 2nd undergraduate degree in Faculty of Philosophy, Pedagogy and Psychology from Kapodistrian University of Athens. PhD degree in Sport Psychology in Kapodistrian University of Athens. Assistant professor in Physical Education and Sport Science from Kapodistrian University of Athens

\section{Michael MITROTASIOS}

Undergraduate degree in Physical Education and Sport Science from Kapodistrian University of Athens. Specialized in "Spezialisierende Fortbildung im Fussball". Master in Deutsche Sporthochschule Köln. PhD in Deutsche Sporthochschule Köln. Lecturer in Physical Education and Sport Science from Kapodistrian University of Athens.

Maria PSYCHOUNTAKI1st undergraduate degree in Physical Education and Sport Science from Kapodistrian University of Athens. 2nd undergraduate degree in Faculty of Philosophy, Pedagogy and Psychology from Kapodistrian University of Athens. PhD degree in Sport Psychology in Kapodistrian University of Athens. Associate professor in Physical Education and Sport Science from Kapodistrian University of Athens. 
